\title{
Group Action Planning As a Support Strategy for Hispanic Families: Parent and Professional Perspectives
}

\author{
Martha J. Blue-Banning, Ann P. Turnbull, and Lourdes Pereira
}

Abstract: Focus group interviews were conducted to obtain participants' preliminary reactions to the responsiveness of group action planning, a person-centered planning approach, as a support strategy for Hispanic families of individuals with disabilities. Focus group participants were 38 Hispanic parents of youth/young adults with developmental disabilities and 22 professionals who provided support services to Hispanic youth/young adults with developmental disabilities and their families. Both constituency groups identified advantages and. disadvantages of group action planning. We focus our key recommendations on the implications of this information for education and human service systems as well as directions for future research.

In recent years, traditional educational and human service planning approaches have received considerable criticism for an emphasis on the deficits of individuals with disabilities and a too frequent focus on what professionals want for individuals rather than on accommodating the individuals' own goals (Butterworth, Steere, \& Whitney-Thomas, 1997; Lakin, 1996; Mount, 1992). Person-centered planning, in contrast, centers on realizing the visions of individuals with disabilities and their families through collaborative partnerships among the individual, family members, friends, professionals, and community members (Mount, 1992; O'Brien \& Lyle, 1987; Turnbull \& Turnbull, 1996). Person-centered planning models include (a) making action plans (Forest \& Pearpoint, 1992), (b) personal futures planning (Mount, 1992), (c) choosing options and accommodations for children (Giangreco, Cloninger, \& Iverson, 1993), and (d) group action planning (Turnbull \& Turnbull, 1996). Although each planning method has idiosyncratic features (e.g., various roles played by parents), these planning methods typically concentrate on individuals' strengths and capacities and on the development and maintenance of networks and relationships that enable them to be integral parts of their communities (Flannery, Slovic, \& McLean, 1994). Hence, through adhering to these methods, service providers help individuals set goals for their quality of life and use local, informal, and generic resources and supports as much as possible to achieve their goals (Butterworth et al., 1997).

Although person-centered planning has increasingly been emphasized in formal service systems, relevant research on this approach is still extremely limited (Hagner, Helm, \& Butterworth, 1996). The focus of most current person-centeredplanning literature is on case studies in which investigators describe planning processes and outcomes (Butterworth et al., 1997; Hagner, Butterworth, \& Keith, 1995; Hagner et al., 1996; Mallate et al., 1992). Reported outcomes include (a) improved social relationships for the individual with a disability, (b) increased mobilization of informal and formal resources, (c) heightened sense of community, (d) shared sense of responsibility, and (e) increased energy experienced by group participants.

To date, no researchers have examined person-centered planning processes with culturally diverse families. United States demographics are 
rapidly changing, with groups characterized by cultural and linguistic diversity comprising a growing segment of the general and special education population (Oswald, Coutinho, Best, \& Singh, 1999). Soon, the largest of these groups will be Hispanic (Children's Defense Fund, 1997). (The term Hispanic generally refers to individuals whose cultural heritage traces back to a Spanish-speaking country with a history of Spanish-American colonization [Harry, 1992]. Many other labels have been used to denote this population, such as Latino, Spanish, and Latin. Currently, there is no consensus among social scientists as to the most acceptable term to use [Marfn \& Marfn, 1991; Soriano, 1991]. In the early 1970s, the federal government adopted the term Hispanic, which has subsequently been designated as the official term for use by the U.S. Bureau of the Census and in all federal publications [Gallegos, 1991; Walker, 19871. For consistency, Hispanic will be the term used throughout this article.) This rapid increase in culturally diverse populations has implications for many aspects of education and human services, including program planning for individuals with disabilities. Increasingly, professionals will work with culturally diverse students and families whose values and beliefs may significantly differ from those of the dominant United States culture to which most professionals belong (Kalyanpur \& Harry, 1999; Lynch \& Hanson, 1998). Addressing the needs of culturally diverse students and their families in program planning requires that service providers recognize and respect the cultural differences of people with disabilities.

The present study, a component of a larger qualitative study, was designed to examine the perspectives of Hispanic parents of youth/young adults with disabilities and professionals who support these families with regard to the effectiveness of person-centered planning to the needs of Hispanic families. We chose group action planning as the person-centered planning method for this research because of its basis on empowering individuals with a disability and family members to create their own visions of the future and to create a reliable alliance among the individual with a disability, family members, professionals, friends, and community members committed to the realization of these visions (Turnbull, Blue-Banning et al., 1996; Turnbull, Turbiville, Schaffer, \& Schaffer, 1996; Turnbull $\&$ Turnbull, 1996). The primary features of action groups include (a) bringing together a network of people committed to active participation in a nonhierarchical, collaborative manner; (b) functioning within a context of social connectedness and caring among all group members; (c) utilizing dynamic and creative problem solving; and (d) continuously affirming group members' contributions and celebrating progress made (Turnbull, Blue-Banning et al., 1996).

\section{Method \\ Participants}

Purposive sampling was used to identify the participants. This sampling method entails sample selection based on participant knowledge of or experience in the topic of interest and possession of characteristics identified by the researchers as selection criteria (Brotherson, 1994). To secure participants at each of four research sites, we contacted professional and personal networks that included Hispanic leaders and leaders of family support groups or organizations/agencies serving families of individuals with disabilities. Through these contacts, a parent of a child with a disability who was a leader in the Hispanic community was selected to serve as the parent coordinator at each site. Researchers worked closely with the parent coordinators to ensure that they had an accurate understanding of the purpose and logistical requirements of the research. These coordinators, in turn, helped to identify parent and professional participants for the focus groups.

Parent participants were 38 Hispanic parents of youth/young adults with developmental disabilities. These youth/young adults represented variation in disability classification (i.e., cerebral palsy, autism, mental retardation); extent of disability (i.e., mild, moderate, severe); geographic variation (i.e., rural, suburban, and urban); and age of individuals with disabilities (i.e., 8 to 26 years). Table 1 presents family demographic information.

The professional sample consisted of 22 professionals (i.e., teacher, school counselor, social worker, vocational rehabilitation counselor) who provided support services to Hispanic youth/young adults (ages 8 to 26 years) with developmental 
Table 1

Parent Demographic Information

\begin{tabular}{|c|c|c|c|c|}
\hline No. & $\begin{array}{c}\text { Gender of } \\
\text { child }\end{array}$ & $\begin{array}{c}\text { Age of } \\
\text { child }\end{array}$ & $\begin{array}{r}\text { Disability } \\
\end{array}$ & Severity \\
\hline $\begin{array}{l}1 \\
2 \\
3\end{array}$ & $\begin{array}{c}M \\
M\end{array}$ & $\begin{array}{l}20 \\
14 \\
19\end{array}$ & $\begin{array}{l}\text { Physical disability } \\
\text { Mental retardation } \\
\text { Learning disability }\end{array}$ & $\begin{array}{l}\text { Severe } \\
\text { Severe } \\
\text { Moderate }\end{array}$ \\
\hline $\begin{array}{l}4 \\
5 \\
6 \\
7 \\
8 \\
9 \\
10 \\
11 \\
12 \\
13 \\
14 \\
15 \\
16 \\
17 \\
18 \\
19 \\
20 \\
21 \\
22 \\
23 \\
24 \\
25 \\
26 \\
27 \\
28 \\
29 \\
30 \\
31 \\
32 \\
33 \\
34 \\
35 \\
36 \\
37 \\
38\end{array}$ & $\begin{array}{c}F \\
M \\
M \\
F \\
M \\
M \\
F \\
F \\
F \\
M \\
M \\
F \\
F \\
M \\
F \\
F \\
M \\
M \\
M \\
M \\
M \\
M \\
M \\
M \\
F \\
M \\
M \\
M \\
M \\
F \\
M \\
F \\
F \\
M \\
F\end{array}$ & $\begin{array}{r}20 \\
13 \\
13 \\
13 \\
17 \\
11 \\
15 \\
14 \\
13 \\
12 \\
17 \\
21 \\
21 \\
21 \\
14 \\
10 \\
18 \\
17 \\
15 \\
17 \\
22 \\
21 \\
20 \\
16 \\
12 \\
11 \\
16 \\
18 \\
11 \\
12 \\
14 \\
9 \\
9 \\
8 \\
8\end{array}$ & $\begin{array}{l}\text { Mental retardation/Physical disability } \\
\text { Mental retardation } \\
\text { Mental retardation } \\
\text { Autism/Mental retardation } \\
\text { Mental retardation } \\
\text { Mental retardation } \\
\text { Mental retardation } \\
\text { Mental retardation } \\
\text { Mental retardation/Physical disability } \\
\text { Mental retardation/Emotional disorder } \\
\text { Learning disability/Physical disability } \\
\text { Mental retardation } \\
\text { Mental retardation } \\
\text { Emotional disorder/Physical disability } \\
\text { Learning disability } \\
\text { Learning disability/Other health impairment } \\
\text { Emotional disorder/Learning disability } \\
\text { Learning disability } \\
\text { Emotional disorder/Learning disability } \\
\text { Learning disability } \\
\text { Mental retardation } \\
\text { Mental retardation/Physical disability } \\
\text { Physical disability } \\
\text { Emotional disorder/Learning disability } \\
\text { Emotional disorder/Learning disabillity } \\
\text { Mental retardation/Other health impairment } \\
\text { Emotional disorder/Learning disability } \\
\text { Mental retardation/Physical disability } \\
\text { Autism } \\
\text { Mental retardation/Physical disability } \\
\text { Mental retardation } \\
\text { Other health impairment } \\
\text { Other health impairment } \\
\text { Mental retardation } \\
\text { Autism }\end{array}$ & $\begin{array}{l}\text { Moderate } \\
\text { Mild } \\
\text { Moderate } \\
\text { Severe } \\
\text { Mild } \\
\text { Severe } \\
\text { Moderate } \\
\text { Moderate } \\
\text { Moderate } \\
\text { Severe } \\
\text { Moderate } \\
\text { Severe } \\
\text { Severe } \\
\text { Mild } \\
\text { Mild } \\
\text { Mild } \\
\text { Severe } \\
\text { Moderate } \\
\text { Moderate } \\
\text { Moderate } \\
\text { Profound } \\
\text { Severe } \\
\text { Mild } \\
\text { Moderate } \\
\text { Mild } \\
\text { Severe } \\
\text { Moderate } \\
\text { Severe } \\
\text { Moderate } \\
\text { Severe } \\
\text { Severe } \\
\text { Profound } \\
\text { Profound } \\
\text { Profound } \\
\text { Mild } \\
\end{array}$ \\
\hline
\end{tabular}

Note. The majority of parent participants (a) were mothers (35), (b) listed their country of origin as Mexico (19) or Puerto Rico (14), (c) were first generation (27), and (d) had incomes below $\$ 15,000$ (22).

disabilities and/or disability-related support services to their families on a weekly or more frequent basis. Because group action planning includes diverse membership, the type of professional was not limited to educational personnel. Table 2 includes professionals' demographic information.

\section{Data Collection}

Focus group interviews served as the datacollection method. This type of group interview is unique because a group of participants typically meets only once (Brotherson, 1994), with the process repeated several times involving different people (Krueger, 1994). The specific intent of focus groups is to provide insights about how people perceive a situation rather than infer, generalize, or make statements about a population (Krueger, 1994). Focus groups afford three particular advantages for this research. First, focus group dialogue creates a synergistic effect, allowing a wider range of information and insight than would private individual responses (Stewart\& Shamdasani, 1990). Second, focus groups are particularly useful when working with individuals who have a history of limited power and influence, such as individuals from culturally and linguistically diverse backgrounds (Morgan, 1993). Third, focus groups provide important information to decision makers before a program or service is initiated, such as in 


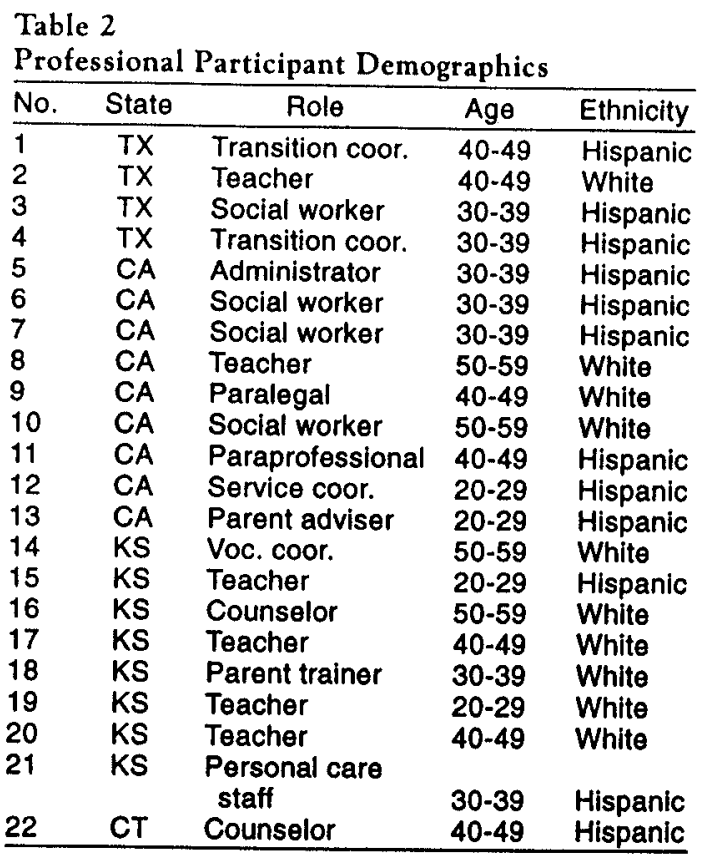

planning and program design (Krueger, 1994). Focus groups also have disadvantages, in cluding (a) lack of opportunity to develop a sense of comfort and rapport with other participants over time and (b) participants' hesitancy to say things in a group context that they might be willing to share in a one-to-one interview.

Focus groups were conducted in four states: (a) Texas, (b) California, (c) Kansas, and (d) Connecticut. These sites were chosen to ensure representation of the two dominant United States Hispanic subgroups, Mexican and Puerto Rican, which currently represent $75 \%$ of the Hispanic population (Massey, Zambrana, \& Bell, 1995; Ortiz, 1995).

At each site, participants attended a 2-hour workshop on group action planning presented in English with simultaneous translation in Spanish. Participants received information about the group action planning process through a workshop format,, which is particularly amenable to creating an adult learning environment that is essential to enhancing participant understanding of group action planning concepts. The workshop highlighted fundamental characteristics of action groups through lecture, discussion, video clips of actual action groups, and handouts. During the workshop, an in-depth description of group action planning was presented, including its five components: (a) inviting support, (b) creating connections, (c) sharing great expectations, (d) solving problems, and (e) celebrating success. Researchers collaborated with translators in advance to ensure translators understood the group action planning process and the workshop agenda. A translation device consisting of a wireless speaker, transmitter, and receiver was used to facilitate seamless translation.

Following the workshop, a 2-hour focus group discussion was conducted to assess participants' reactions to the responsiveness of group action planning as a support strategy for Hispanic families. We projected that one parent focus group and one professional focus group would be held in each of the four research sites. These initial parent groups combined English-speaking parents with Spanishspeaking parents. Mixing language preference in the parent focus groups, however, proved unwise because the required translation inhibited the free flow of discussion. As a result, parent focus groups were divided according to the primary language of the participants. A Hispanic member of the research team, fluent in Spanish, moderated the Spanishspeaking parent focus groups.

Because three facilitators were used, the agenda for focus group discussions was set by an interview guide to avoid language variance that could alter intent (Krueger, 1994; Miles \& Huberman, 1994) Facilitators were, however, flexible and prepared to adapt or change questions so that participants could shape the direction of the discourse (Stainback \& Stainback, 1989). All focus group interviews were taperecorded and transcribed.

\section{Data Analysis}

Data collection and analysis occurred concurrently and recursively throughout the study. Analysis of each group interview enabled us to identify areas needing clarification, confirmation, or exploration and; therefore, assisted in shaping and focusing subsequent data collection (Brotherson, 1994). The mechanical aspects of physically organizing the data were facilitated by the Ethnograph, a qualitative analysis soft ware program designed to organize and retrieve textual data (Knodel, 1993).

Data reduction began immediately after fieldwork. Following each focus group, the facilitators debriefed, comparing notes and observations. During this data-reduction phase, 450 single-spaced pages of transcripts (in addition to field notes and debrief summaries) were read and reread. Four members of the research team participated in the 
category-development phase. First, they independently read each transcript to establish the essence of what was said and to get an overall sense of the data. Next, they reread the transcripts, highlighting segments that seemed important and relevant. They noted ideas about patterns and themes in the right-hand margins.

Team members then met to discuss their individual findings as a basis for developing a list of internally consistent, discrete categories (Marshall \& Rossman, 1995). This process brought together segments related to the same content under categorical headings that provided an organizational theme for the units of data (Vaughn, Schumm, \& Sinagub, 1996).

Team members developed a preliminary operative coding framework from the list of categories as well as the research questions, interview questions, and concepts/categories from other researchers or related studies (Tesch, 1990). Code names were assigned to categories that were closest to the concepts they described.

Two members of the research team then reread the transcripts, applying the coding framework and examining it for fit (Miles \& Huberman, 1994). Although several codes were revised, the overall framework seemed compatible. As we analyzed new data, codes were collapsed or combined based on similarities, frequency of occurrence, and emerging themes and patterns (Gallivan-Fenlon, 1994; Marshall, \& Rossman, 1995).

At this point of analysis, the researchers conducted a peer debriefing with a colleague who had substantive knowledge of the research topic but was an outsider to the project (Brotherson \& Spillers, 1989; Lincoln \& Guba, 1985; Miles \& Huberman, 1994). A second peer debrief was conducted during the interpretation and conclusiondrawing phase.

Two researchers participated in the next facet of data reduction, check-coding, which clarified category definitions (Miles \& Huberman, 1994). Using the established code list, the two researchers independently coded a clean copy of each transcript. The coded transcripts, including redundancies, were then entered into Ethnograph.

The same two researchers then each took a complete set of Ethnograph output files and independently determined whether the segment of text fit the coded category. They compared their interpretations of the coded materials. When the researchers disagreed, they discussed the text and code/category in question until reaching consensus (Hanley- Maxwell, Whitney-Thomas, \& Pogoloff, 1995).

During the final data-analysis activity, interpretation and conclusion drawing, researchers drew the essential meaning from focus group participants' words. During this phase, they examined the coded data, further clarifying definitions of concepts and uncovering the connections and relationships among them (Gilgiun, Daly, \& Handel, 1992).

\section{Trustworthiness}

Numerous strategies were implemented to ensure trustworthiness. Many were employed at the operational level, including (a) multiple informants (i.e., different groups of family members and professionals), (b) member checks at the end of each focus group, (c) multiple researchers and analysts, (d) comparable data-collection protocols, (e) coding checks (inter and intrarater agreement), (f) verbatim transcripts providing thick descriptions, and $(\mathrm{g})$ peer debriefs. In addition, a comprehensive member check was conducted at the end of the research project to evaluate the interpretative fairness and validity of the analysis from the perspectives of the original participants (Lincoln \& Guba, 1985; Patton, 1990; Seidman, 1991). One professional and two family member participants from each research site agreed to review the research findings. Each reviewer was sent a packet containing a cover letter, profes sional or parent focus group summary report, and a onepage response form. The response form contained questions inquiring whether (a) the summary was a reasonable interpretation of the focus group discussion, (b) notable points had been left out, and (c) the reviewer had concluding comments or suggestions. Based on their personal preferences, member check participants provided either written or verbal feedback. Their responses were confirmatory and increased researchers' confidence that the data analysis represented stakeholder reality.

\section{Limitations of the Study}

The results of this inquiry must be interpreted cautiously in light of several factors. First, participants were members of and/or had received services (e.g., attended workshops) from family support organizations whose representatives collaborated 
with the researchers to obtain samples. Therefore, they may have been more knowledgeable and involved than is typical in their Hispanic communities. Second, it is important to note that these participants had not actively participated in an action group. Participants attended a workshop on group action planning and then participated in focus group interviews for the purpose of assessing their preliminary reactions to the responsiveness of group action planning as a support strategy for Hispanic families. Third, the Hispanic participants' positive responses to group action planning may have been influenced by the desire to promote a more positive encounter with researchers according to a Hispanic collectivistic orientation (Magana, 1999; Zuniga 1998). Fourth, although focus groups provided important advantages for this research, this data-collection method limited the opportunity for researchers to develop rapport with participants over time. Finally, the four geographical locations were specifically selected to (a) ensure representation of the two dominant Hispanic subgroups in this country, Mexican and Puerto Rican, and (b) avoid constructing a community representative of all Hispanics. It is important, however, to emphasize that Hispanics are a heterogeneous population, living in all areas of the United States and representing differing levels of acculturation. Too often in the literature, broad generalizations have been made concerning Hispanic families. Caution must be taken to eliminate the possibility of oversimplifying the results of this study.

\section{Findings}

Responses from parent and professional groups related to group action planning were combined into two major categories: (a) perceived advantages and (b) perceived disadvantages. It is important to note that group action planning generated much more conversation in the parent focus groups than in the professional groups. The following section includes family members' responses, followed by those of professionals.

\section{Perceived Advantages: Parent Perspectives}

Parent participants made many more comments about the advantages rather than the dis advantages they perceived in group action planning. Overall, they indicated this type of planning process could increase both the quality and quantity of accomplishments for their son or daughter. These positive comments fell into two subcategories: teamwork and flexibility.

Teamwork. In all four geographical locations, the benefit of group action planning that parents most emphatically identified was "the concept ... of the team work, of working together. If each one does a little, takes a step, there will be several steps." At the heart of this issue was the advantage of having a committed group of people working together for their son or daughter who "are not going to say: 'They (the parents) have the problem, they are going to provide for everything'." The most appealing element of group action planning appeared to be cooperation and partnership with a diverse group of people.

Throughout the focus groups, parents frequently discussed the issue of parents bearing the total responsibility for meeting their child's needs. With reference to group action planning, however, many parents talked about the emo tional relief of no longer feeling that "the cross is ours ... and [that] we are not put [sic] the weight on anybody [else]." As one parent said, "Simply that sharing it [the responsibility] with others, it feel less heavy and [that] is everything." Similarly, a mother who had been clearly tense throughout most of the focus group dis cussion visibly relaxed as she talked about how she would feel to have a group of people sharing the responsibility of meeting her son's needs:

That [sharing the responsibility] would be so relaxing ...because I haveso much tension.... It's almost like everything is on me, everything, and if I let everybody else in the family and the community in it, I can relax a little, sit back and say, 'Wow, it's not all on me now and everybody is helping me.'

Parents envisioned that sharing responsibility would enhance their ability to accomplish their goals by "breaking down [and] assigning tasks," thereby reducing the fear of facing too formidable a task:

Usually the parents are the ones who are trying to accomplish these things, and if you get the group action plan together, you get certain people to do certain things.... We get to see maybe something weve never seen before in that with just a little bit of help we can accomplish the big goal.... It breaks the fear, or that barrier that, you know, this is such abigjob. 
Parents frequently pointed out how much more could be achieved when a group of people were working together than when they worked in isolation. They voiced the belief that "where there are different viewpoints, they will give different alternatives" resulting in "better successes."

In addition to the benefit of not carrying the full responsibility alone, parents noted that another teamwork advantage of group action planning would be having the opportunity to evaluate their own decisions more clearly. For one mom, having a group of trusted people to "bounce" ideas off of increased her confidence in her decisions and actions: "The group dynamics answer ... questions I have of what I'm doing." Likewise, several parents said that group action planning would provide them with opportunities to see situations through other individuals' eyes, allowing parents to evaluate their own perspectives.

Flexibility. Parents said that the versatility of group action planning was a positive aspect. Parents saw this planning process as a malleable support that met diverse needs resulting from different disabilities, "It's flexible. It's a living kind of thing that you can mold it to whatever situation you need, whether it's somebody with severe challenges [or] ... mild."

Parents also identified the flexibility of action group membership as an advantage. They unanimously supported the idea of having decisionmaking power concerning their child's action group membership: "We [parents] would get to choose who we wanted to be in this [action group] ... not just choose so and so because he has a degree." Some parents felt it was essential to begin with immediate family members. Siblings of the child with the disability were particularly envisioned as essential action group members. Many parents, however, who envisioned the need to involve friends and neighbors warned that "we are... limiting ourselves among each other" by only including family members and professionals. Parents also discussed the importance of including a person of authority who was respected and trusted within the community, such as a priest or pastor.

Throughout the focus group discussions, parents were emphatic about cautiously selecting individuals to be members of their child's action group. Trust was an important factor in this regard because parents perceived that the family would share intimate facts about themselves with other group members. Several parents noted that this was especially necessary for Hispanic families:
We, Latino, ... for us to say I feel like this and this [to another individual], we have to ... trust that person. .. I think that one should be very careful and that would be the task, to know how to select ... the people that you want to be in the circle.

\section{Perceived Advantages: Professional Perspectives}

Similar to parents, most professionals indicated that they perceived group action planning as beneficial. However, the majority of their comments were directed externally-most advantages were referred to as being advantageous to family members. Professionals perceived group action planning as providing little benefit to themselves in accomplishing job-related functions associated with supporting individuals with disabilities and their families. The positive factors identified by professional participants focused on three areas: family benefit, environmental advantages, and improved communication.

Family benefit. Overall, professionals perceived group action planning as useful for parents, particularly as a means of educating families: "It [group action planning] would tend to educate the family about how they could meet their needs." For example, group action planning was viewed as an effective mechanism for informing families about resources available in their community.

Environmental advantages. Several profes sionals suggested that in contrast to traditional planning processes, the environment afforded by group action planning would reduce parental intimidation. They liked the idea of the more "intimate," "wholer, more comfortable" atmosphere where individuals could "meet and ... talk about the issue ... but at the same time within a climate of enjoying it."

In addition, several educational professionals pointed out that they were encumbered by legally mandated paperwork and the threat of due process, causing them to place emphasis on the legalistic aspects of special education. As one professional said, "The professional is sitting there going, 'Am I following all the guidelines or am I handling everything the way I should legally to be challenged by due process?' because these are natural threats that we also have." The group action planning context provided the opportunity to refocus on the student:

You're kind of freed from the pressure that we have, where it's that IEP meeting has become so much a focus of that piece of paper rather than [the] student and you have the opportunity to actually concentrate on the needs of the student. 
Improved communication. Improved communication between professionals and parents was perceived by a few professionals as an asset of group action planning, "The ideas, sometimes you [professionals and parents] get bottled up in some situations, and I think with an action group ...the ideas will float maybe a lot easier." Several professionals emphasized that group action planning provided the opportunity for expression of multiple points of view, "not just the student point of view, or the parents' or the teachers', but all three," which would enable group members to learn from one another.

\section{Perceived Disadvantages: Parent Perspectives}

Parent participants also identified disadvantageous factors related to action groups, including vulnerability and time commitment.

Vulnerability. The majority of comments related to negative aspects of group action planning focused on issues of vulnerability. That is, parents presumed that participating in a planning process, such as group action planning, would put them in a vulnerable position. Specifically, many parents commented that it would be difficult for them to invite people to be a part of their child's action group, even though they recognized the advantage of having some control over the group's membership. They perceived that asking others for support opened opportunities for rejection: "You don't know whether you would get turned down or they say, 'Well, that's your child."' The "fear of rejection ... no support" was commonly expressed related to inviting others to be action group members.

Parent participants also raised concerns about sharing family issues with others. Their comments suggested that some parents were reticent to share suggestions and dreams with others for fear that their ideas would be rejected:

For me it would be very difficult, very frustrating to expose my ideas, my dreams. Because all parents we wanthe best for our children and [if] this [is] not being understood nor supported, I think that would be very painful. Many times, that is why we do not suggest, we do not say it ... we keep it for ourselves.

Another parent concern related to a universal need of wanting others to see them in the best possible light. Parents were concerned that by making their lives "public" to a group of people, they would be allowing those individuals to see an unfavorable side of them:

It is difficult to invite other people to enter in our lives... because we... want to make it the most beautiful ... possible... So, to invite other people ... outsiders, is to see things that we really do not want them to see.

Time commitment. The time commitment in group action planning was another disadvantage identified by a few parent participants. At the heart of their concern was the fact that other individuals are busy and may not have the time or be willing to give the time to an action group: "I would invite my sisters, but I see a 'but'.... the 'but' is that when the times arrives, everyone has [other] things to do ... everybody has an occupation."

\section{Perceived Disadvantages:}

Professional Perspectives

Professionals' comments about negative aspects of group action planning focused primarily on issues related to professional time commitments. It was clear that professionals, already feeling overworked by multiple tasks and legally required "paperwork" that "is tripling every year," questioned the feasibility of implementing this planning process for all the individuals with whom they worked. One participant expressed the view of many about the obstacle they perceived imposed by the time commitment of group action planning,

If you're talking about Latinos ... people working the fields. [Their] hours vary ... it would put a lot of pressure on us [the professionals]. We would probably have to do extra work ... work like at night and go to their home.

For these reasons, professional participants suggested incorporating group action planning concepts into current planning methods rather than implementing the process as a whole. They also suggested limiting the use of action groups to individuals "who may need it more than others" and involving only those professionals "who you know are willing to go the extra mile, put in a little extra time and care enough to really want to be involved."

\section{Discussion}

In this study we obtained reactions from parents and professionals about the effectiveness of a person-centered planning approach, namely, group action planning, for Hispanic families of youth/young adults with developmental disabilities. In this section we discuss the findings across both constituent groups and suggest directions for future research. 


\section{Parent Perspectives}

Both parents and professionals identified group action planning as beneficial for families. In this regard, parents focused primarily on aspects of collaboration and support. It was clear that they felt a disparity of power and authority in their relationships with professionals within traditional service provision. In essence, parents perceived that they had little power in decisions concerning their child.

With regard to group action planning, parents identified teamwork as a major advantage, anticipating that the collaborative element of action groups would result in increased accomplishments for their child. Indeed, cooperation and equitable partnership appeared to be the most appealing element of group action planning to parent participants. As one parent noted, "Two heads think better than one." Turnbull, Turbiville, Turnbull, Garland, and Lee (1996) described this collaborative effort as a "synergistic community":

A synergistic community is one in which all participants generate increased activity and energy (Craig \& Craig, 1974)so that the "whole is greater than the sum of the parts." In such a context, each person's efforts significantly and exponentially advance individual and group goals, as well as enhancing each participant's motivation and knowledge/skills. (p. 33)

Many parents also emphasized the importance of families receiving informal support from other family members, friends, neighbors, churches, and community members. The support offered by these sources has been identified as the most essential and effective (Fewell \& Vadasy, 1986), serving as a buffer from the stress of negative life events (Dunst, Trivette, Gordon, \& Pletcher, 1989). Familism, a cultural feature that is widely recognized in the literature to be associated with the Hispanic population, refers to family unity and interdependence (Hidalgo, 1992). In a study exploring the role of familism in caregiving for Puerto Rican mothers, Magana (1999) found that lower depressive symptoms were most strongly associated with two aspects of familism: the size of the mother's social support network and her satisfaction with social support. Therefore, it is not surprising that parent participants in this research ardently embraced the idea of working together with others as a team to achieve visions for their child. In particular, they discussed the emo tional relief of sharing the responsibility of meeting their child's needs with others whom they trusted.
There are several possible reasons why parents felt this way. The first reason relates to an undercurrent of thought that was evident throughout parent discussions, namely, that parents sustained the full responsibility of meeting their child's needs. Parents clearly indicated that they lacked adequate support and identified how much they valued and needed support. Therefore, it is not surprising that they ardently embraced the idea of working together with others as a team to achieve visions for their child. This finding is corroborated by Turnbull, Turnbull, and Blue-Banning (1994), who suggested that a group of people empowered across all ecological areas ameliorates the need for families to initiate and assume the total responsibility of meeting their child's needs:

Often, the literature on family functioning has emphasized the additional caretaking demands of children with disabilities, but it has failed to identify the fact that many of the additional caretaking responsibilities are because no other family, neighborhood, and community supports are being provided. Thus, rather than viewing additional responsibilities as an inherent as pect of the disability, a key recognition is that there needs to be a greater focus on problem solving and empowerment of all people within the ecological network of children and families to make sure that they are able to make their contributions. (p. 11)

The second reason relates to the Hispanic culture's collectivistic orientation, which emphasizes a cooperative view of life (Magana, 1999; Zuniga 1998). Individuals from collectivist cultures tend to avoid competition, to stress cooperation, and to have strong family ties. Gutibrrez (1995) identified active collaboration as important to many Hispanic families and as generally compatible with the Hispanic culture's collective orientation.

Empowerment practice's emphasis on participation ... is very compatible with many Latino communities. $A$ core cultural concept for Latinos is personalismo: developing a personal relationship and understanding before beginning to work (Applewhite \& Daley, 1988). By taking the time to get to know the family and how they see their situation, staff communicate respeto (respect), another important element of Latino social interactions. Latino culture is structured around hierarchies and based on notions of giving proper respect to those with more power. In order for open communication to take place, a reduction of power imbalance may be necessary. This suggests that the collaborative focus, of empowerment practice can be particularly appropriate with Latinos. (p. 7)

(In using this quote, we do not want to suggest that there is total homogeneity on these core cultural concepts among Hispanic families. It is 
essential to recognize that cultural attributes are tendencies, not absolutes, and are not rigidly fixed to any one individual or family [Anderson, 1994)].)

Although parents were resolute about the benefits of sharing responsibility with others, they were equally earnest about the vulnerability such cooperation might bring. They particularly expressed fear of (a) rejection (as a result of inviting others to participate in action groups and being told no), and (b) exposure (by publicly opening areas of family life). O'Connor (1995) reported a similar finding in a study examining the meaning of support services to families:

The families entered this [human services] system because a member of the family needed support and practical assistance in connection with a disability... . Rather than simply receiving the assistance they sought, the families found themselves involved in a process of changing the family identity, with professionals sometimes viewing them as clients, judging them as good or bad parents, counseling and advising them, and attempting to modify their attitudes.... This is a departure from the private world of relative autonomy and anonymity to the public world of exposure, scrutiny, and judgment.... Families entering a system for support often anticipate receiving help, but they become increasingly aware that they are losing some privacy... . Often this awareness of loss of privacy accompanies the realization of how information they have shared has been used. (p. 200)

Likewise, Hatton (1998) cautioned that the use of subjective quality of life assessments can increase the power that professionals have over individuals with disabilities. (Because group action planning primarily focuses on quality of life considerations, his point is relevant within this context.) Hatton warned that an openness about the nuances of people's lives can result in invasion of privacy and even result in "surveillance" (p. 110). The fundamental issue is the balance of power between the family and the service system.

Parents were, therefore, emphatic about the need to be cautious when selecting members of their action group, choosing only individuals they trust. Respected and trusted persons of authority within the community, such as a priest or pastor, were considered excellent potential group members. Reliability and trust were two characteristics frequently mentioned in the supportive, collaborative relationships that parents discussed. Indeed, trust has been identified as an essential element of any genuine partnership (Turnbull \& Turnbull, 1997). Singer and Powers
(1993) described this type of a relationship as a "reliable alliance," identifying two elements of a reliable alliance that were also reflected in parents' responses in this study:

One aspect of reliable alliance is instrumental and practical in the sense that concrete facts of availability and repeated support over time help to establish a sense of enduring trustworthiness. The second aspect of reliable alliance is affective ... [and] consists of the perception that intersubjectivity has been attained. Intersubjectivity is the perception that persons' subjective experiences overlap.... Commonality of experience is not the sole constituent of intersubjectivity. There also must be a mutual attribution of positive intent in the relationship. (p. 14)

These findings support a basic premise of person-centered planning, that the individual and family are empowered to take an active role in all planning decisions, such as the selection of planning group members.

\section{Professional Perspectives}

It is interesting to note that the majority of professional comments related to positive factors were directed externally, whereas all comments related to negative factors related to themselves. Professional comments related to group action planning were much less personal and more detached than those of the parents. In essence, it appeared that professionals perceived group action planning as a tool to be used by others. It is particularly noteworthy that many professionals saw education of parents as the greatest benefit of this collaborative planning process. This may reflect the emphasis placed on parent training and education in the disability field (Boone, 1992).

Some professionals also said that the environment afforded by group action planning would create a more personal and nonthreatening environment for parents. This finding is similar to the experiences of other educator and family member action group participants who reported action groups to be enjoyable and socially connected (Turnbull \& Turnbull, 1997). Environmental factors have been identified as necessary in setting the stage for collaborative partnerships (Walker \& Singer, 1993). A responsive context, one that facilitates the development of collaborative partnerships, is characterized by opportunities for enjoyable and reciprocal relationships (Turnbull, Blue-Banning et al., 1996; Turnbull \& Turnbull, 1997). Giving sufficient regard to the context of relationships 
and agreements is essential to successful personcentered planning. Building and strengthening personal relationships is at the heart of the process (O'Brien, O'Brien, \& Mount, 1997). Zuniga (1998) noted that the environmental factor may be particularly relevant for Hispanic families as a result of the Hispanic cultural value of personalismo, which is predicated on warm, individualized attention and responsiveness in interpersonal interactions. This value creates the need for a more humanistic orientation, rather than the task-oriented style typical of so many professionals.

Professionals, however, identified few advantages of group action planning for themselves. They appeared to perceive group action planning as an "add-on" to work schedules that were already too full. Thus, although professionals saw benefit to action groups for families, they identified little benefit for themselves; rather, they viewed them as quite a liability in terms of time commitment. O'Brien, O'Brien, and Mount (1997) cautioned that true person-centered planning cannot be an appendage to a professional's schedule. They emphasized that person-centered planning works only if it is applied "mindfully" and that mindful work involves personal commitment and action outside of systemscheduled meetings.

In addition to time constraints, there may be several reasons why few professionals identified group action planning as of benefit to themselves. One reason may involve professional autonomy. Skrtic (1995) noted that professionals are granted greater autonomy by society than are other social groups. Indeed, professional autonomy is considered by most social scientists as the ultimate criterion of professionalism. In addition, Walker and Singer (1993) pointed out that decades of neglect of collaboration in professional training programs have left professionals ill-prepared to facilitate collaborative parent-professional partnerships. Perhaps the emphasis on professional autonomy, plus a lack of emphasis on collaboration in professional training programs limits professionals' capacity to perceive collaborative processes as beneficial to themselves. Indeed, the type of planning process studied here may place professionals in a role that is foreign to their professional training, thereby rendering them uncertain and vulnerable.

Another reason for professionals' reluctance to embrace group action planning may relate to the problem-solving method integral to group action planning and other person-centered planning processes (Mount, 1992; Turnbull, Turbiville et al., 1996). Frequently, creative and systematic problem-solving is absent in traditional team meetings (Turbiville et al., 1996). Moreover, many professionals may not have good problemsolving skills and may see no need for such skills. As Skrtic (1995) noted:

Professional practice is a matter of pigeon-holing a presumed client need into one of the standard practices in the professional's repertoire of skills.... Professionals are performers, not problem solvers. They perfect the standard practices in their repertoire of skills. They do not invent new practices for each unique need. (p. 758)

These findings indicate a need for the curricular content of professional preparation programs (i.e., teacher education programs) to concentrate on training in the development of collaborative relationships with families. A single course is not adequate to prepare profes sionals to develop partnerships with families. Training should occur in multiple formats, including coursework and first-hand experience with families. In addition, ongoing staff development efforts need to be focused on assisting current professionals to develop collaborative teaming skills.

Finally, several educators discussed the challenges presented by mandated paperwork and the threat of due process. The special education legalistic framework may place parents and educators in adversarial positions (Kalyanpur \& Hary, 1999), making the development of collaborative partnerships even more difficult.

These findings raise critical questions about the need to examine issues related to the compatibility of the current educational and human service systems and parent/professional collaboration. Are professionals caught in a conflict of interest between the "system" in which they work and the individuals with disabilities and families whom they allege to support? Is special education's legalistic framework a catalyst for and at the same time barrier to collaboration? In addition, an important area for future inquiry is the broad-scale implementation of personcentered planning within large systems while maintaining the integrity of the process. Or can personcentered planning be incorporated into already existing service systems' planning processes as suggested by the professional participants in this study?

In summary, parent participants indicated that one 
form of person-centered planning, group action planning, may be an effective support for Hispanic families of youth/young adults with disabilities. Although professional participants agreed, they found little benefit for themselves. Results of this study reveal a need for more information regarding the processes and outcomes of group action planning implementation for Hispanic individuals with disabilities, families, professionals, and friends/community members.

\section{References}

Boone, R. (1992). Involving culturally diverse parents in transition planning. Curriculum Development and Educational Instruction, 15, 205-22 1.

Brotherson, M. J. (1994). Interactive focus group interviewing: A qualitative research method in early intervention. Topics in Early Childhood Special Education, 14, 101-118.

Brotherson, M. J., \& Spillers, C. S. (1989). A qualitative study on families with disability at two periods of transition in the life cycle. Unpublished manuscript, University of Kentucky.

Butterworth, J., Steere, D. E., \& Whitney-Thomas, J. (1997). Using person-centered planning to address personal quality of life. In R. L. Schalock \& G. N. Siperstein (Eds.), Quality of life volume II: Application to persons with disabilities ( $\mathrm{pp}$. 5-23). Washington, DC: American Association on Mental Retardation.

Children's Defense Fund. (1997). The state of America's children: Yearbook 1997. Washington, DC: Author.

Craig, J. H., \& Craig, M. (1974). Synergic power: Beyond domination and permissiveness. Berkeley, CA: Proactive Press.

Dunst, C. J., Trivette, C. M., Gordon, N. J., \& Pletcher, L. L. (1989). Building and mobilizing informal family support networks. In G. H. S. Singer \& L. K. Irvin (Eds.), Support for care giving families: Enabling positive adaptation to disability (pp. 121-142). Baltimore: Brookes.

Fewell, R. R., \& Vadasy, P. F. (1986). Families of handicapped children: Needs and supports across the life span. Austin, TX: PRO-ED.

Flannery, K. B., Slovic, R., \& McLean, b. (1994). Person centered planning: How do we know we are doing it? Salem: Oregon Transition Systems Change Project, Oregon Department of Education.

Forest, M., \& Pearpoint, J. C. (1992, October). Put ting all kids on the MAP. Educational Leadership, pp. 26-31.

Gallegos, J. S. (1991). Culturally relevant services for Hispanic elderly. In M. Sotomayor (Ed.), Empowering Hispanic families: A critical issue for the '90's (pp. 173-190). Milwaukee, WI: Family Service America.

Gallivan-Fenlon, A. (1994). "Their senior year":
Family and service provider perspectives on the transition from school to adult life for young adults with disabilities. Journal of the Association for Persons with Severe Handicaps, 19, 11-23.

Giangreco, M. F, Cloninger, C., \&Iverson. (1993). Choosing options and accommodations for children $(\mathrm{COACH})$ : A guide to planning inclusive education. Baltimore: Brookes.

Gilgun, J. G., Daly, K., \& Handel, G. (Eds.). (1992). Qualitative methods in family research. Newbury Park, CA: Sage.

Guti6rrez, L. M. (1995). Empowerment and Latinos: Implications for practice. Family Resource Coalition Report, 13(III \& IV), 5-8.

Hagner, D., Butterworth, J., \& Keith, G. (1995). Strategies and barriers in facilitating natural supports for employment of adults with severe disabilities. Journal of the Association for Persons with Severe Handicaps, 20, 110-120.

Hagner, D., Helm, D. T., \& Butterworth, J. (1996). "This is your meeting": A qualitative study of personcentered planning. Mental Retardation, 34, 159171.

Hanley-Maxwell, C., Whitney-Thomas, J., \& Pogoloff, S. M. (1995). The second shock: A qualitative study of parents' perspectives and needs during their child's transition from school to adult life. Journal of the Association for Persons with Severe Handicaps, 20(1), 3-15.

Harry, B. (1992). Cultural diversity, families, and the special education system. New York: Teachers College Press.

Hatton, C. (1998). Whose quality of life is it anyway? Some problems with the emerging quality of life consensus. Mental Retardation, 36, 104-115.

Hidalgo, N. M. (1992). "1 saw Puerto Rico once": A review of the literature on Puerto Ricanfamilies and school achievement in the United States (Rep. No. 12). Baltimore: Johns Hopkins University, Center on Families, Communities, Schools, \& Children's Learning.

Kalyanpur, M., \& Harry, B. (1999). Culture in special education: Building reciprocal family-professional relationships. Baltimore: Brookes.

Knodel, J. (1993). The design and analysis of focus group studies: A practical approach. In D. L. Morgan (Ed.), Successful focus groups: Advancing the state of the art (pp. 35-50). Newbury Park, CA: Sage.

Krueger, R. A. (1994). Focus groups: A practical guidefor applied research (2nd ed.). Thousand Oaks, CA: Sage.

Lakin, K. C. (Ed.). (1996). Research on community integration of persons with mental retardation and related conditions: Current knowledge, emerging challenges, and recommended future directions [Preliminary report]. Washington, DC: U. S. Department of Education, National Institute on Disability and Rehabilitation Research.

Lincoln, Y. S., \& Guba, E. G. (1985). Naturalistic inquiry. Newbury Park, CA: Sage.

Lynch, E. W., \& Hanson, M. J. (1998). Developing 
cross-cultural competences: A guide for working with children and their families. Baltimore: Brookes.

Magana, S. M. (1999). Puerto Rican families caring for an adult with mental retardation: The role of familism. American Journal on Mental Retardation, 104,466-482.

Mallete, P., Mirenda, P., Kandborg, T., Jones, P., Bunz, P., \& Rogow, S. (1992). Application of lifestyle development process for persons with severe intellectual disabilities: A case study report. Journal of the Association for Persons with Severe Handicaps, 17, 179-191.

Marfn, G., \& Marin, B. V. (1991). Research with Hispanic populations. Newbury Park, CA: Sage.

Marshall, C., \& Rossman, G. B. (1995). Designing qualitative research. Thousand Oaks, CA: Sage.

Massey, D. S., Zambrana, R. E., \& Bell, S. A. (1995). Contemporary issues in Latino families: Future directions for research, policy, and practice. In R. E. Zambrana (Ed.), Understanding Latino families: Scholarship, policy, and practice (pp. 190-204). Thousand Oaks, CA: Sage.

Miles, M. B., \& Huberman, A. M. (1994). Qualitative data analysis: A sourcebook of new methods. Newbury Park, CA: Sage.

Morgan, D. L. (Ed.). (1993).. Successful focus groups: Advancing the state of the art. Newbury Park, CA: Sage.

Mount, B. (1992). Personal Futures Planning: Promises and precautions. New York: Graphic Futures.

O'Brien, J., \& Lyle, C. (1987). Framework for accomplishment. Decatur, GA: Responsive Systems Associates.

O'Brien, C. L., O'Brien, J., \& Mount, B. (1997). Person-centered planning has arrived ... or has it? Mental Retardation, 35, 480-484.

O'Connor, S. (1995). "We're all one family": The positive construction of people with disabilities by family members. In S. J. Taylor, R. Bogdan, \& Z. M. Lutfiyya (Eds.), The variety of community experience (pp. 67-77). Baltimore: Brookes.

Ortiz, V. (1995). The diversity of Latino families. In R. E. Zambrana (Ed.), Understanding Latino families. Scholarship, policy, and practice (pp. 18-39). Thousand Oaks, CA: Sage.

Oswald, D. P., Coutinho, M. J., Best, A. M., \& Singh, N. N. (1999). Ethnic representation in special education: The influence of school-related economic and demographic variables. Journal of Special Education, 32, 194-206.

Patton, M. Q. (1990). Qualitative evaluation and research methods. Newbury Park, CA: Sage.

Seidman, 1. E. (1991). Interviewing as qualitative research: A guide for researchers in education and the social sciences. New York: Teachers College Press.

Singer, G. H. S., \& Powers, L. E. (1993). Contributing to resilience in families: An overview. In G. H. S. Singer \& L. E. Powers (Eds.), Families, disability, and empowerment: Active coping skills and strategies for family interventions ( $\mathrm{pp}$. 1-25). Baltimore: Brookes.

Skrtic, T. M. (1995). The crisis in professional knowledge. In E. L. Meyen \& T. M. Skrtic (Eds.), Special education and student disability: An introduction (4th ed., pp. 567-607). Denver, CO: Love.

Soriano, F I. (1991). U.S. Hispanics and their families: A sociocultural portrait. Paper prepared for the International Conference on the Unity of Sciences, Seoul, Korea.

Stainback, W., \& Stainback, S. (1989). Using qualitative data collection procedures to investigate supported education issues. Journal of the Association for Persons with Severe Handicaps, 14, 271-277.

Stewart, D. W., \& Shamdasani, P. N. (1990). Focus groups: Theory and practice. Newbury Park, CA: Sage.

Tesch, R. (1990). Qualitative research: Analysis types and software tools. New York: Falmer Press.

Turbiville, V. P., Turnbull, A. P., Garland, C. W., \& Lee, I. M. (1996). Development and implementation of IFSPs and IEPs: Opportunities for empowerment. In S. L. Odom \& M. E. McLean (Eds.), Early interventionearly childhood special education: Recommended practices (pp. 77-100). Austin, TX: Pro-Ed.

Turnbull, A. P., Blue-Banning, M. J., Anderson, E. L., Turnbull, H. R., Seaton, K. A., \& Dinas, P. A. (1996). Enhancing self-determination through group action planning: A holistic emphasis. In D. J. Sands \& M. L. Wehmeyer (Eds.), Self-determination across the life span: Independence and choice for people with disabilities (pp. 237-256). Baltimore: Brookes.

Turnbull, A. P., Turbiville, V., Schaffer, R., \& Schaffer, V. (1996). "Getting a shot at life" through Action Planning. Zero to Three, 16(6), 3340.

Turnbull, A. P., \& Turnbull, H. R. (1996). group action planning as a strategy for providing comprehensive family support. In L. K. Koegel, R. L. Koegel, \& G. Dunlap (Eds.), Positive behavioral support: Including people with difficult behavior in the community (pp. 99-114). Baltimore: Brookes.

Turnbull, A. P., \& Turnbull, H. R. (1997). Families, professionals, and exceptionality: A special partnership (3rd ed.). Upper Saddle River, NJ: Merrill/ Prentice Hall.

Turnbull, A. P, Turnbull, H. R., \& Blue-Banning, M. J. (1994). Enhancing inclusion of infants and toddlers with disabilities and their families: A theoretical and programmatic analysis. Infants and Young Children, 7(2), 1-14.

Vaughn, S., Schumm, J. S., \& Sinagub, J. (1996). Focus group interviews in education and psychology. Thousand Oaks, CA: Sage.

Walker, B., \& Singer, G. H. S. (1993). Improving collaborative communication between professionals and parents. In G. H. S. Singer \& L. E. Powers (Eds.), Families, disability, and empowerment: Active coping skills and strategies for familyinterventions (pp. 285326). Baltimore: Brookes.

Zuniga, M. E. (1998). Families with Latino roots. In E. W. Lynch \& M. J. Hanson (Eds.), Developing crosscultural competence: A guidefor working with children 
and their families (pp. 209-250). Baltimore:

Brookes.

Received 4/30/98, first decision 6/10/98, accepted 11/2/99.

Editor-in-Charge: Steven J. Taylor
Authors: MARTHA BLUE-BANNING, PhD, Research Associate, and ANN P. TURNBULL, EdD, Co-Director, Beach Center on Families and Disability, University of Kansas, 3111 Haworth Hall, Lawrence, KS 66045-2930. LOURDES PEREIRA, MA, Adjunct Professor, Georgia Perimeter College, 2102 Womack Rd. Dunwoody, GA 30308.

This research was supported by a grant from the National Institute on Disability and Rehabilitation Research to the Beach Center on Disability, Grant \#H133B30070.

\section{Innovations Invitation for Submissions}

\section{About the Series}

Innovation is a publication of the American Association on Mental Retardation that brings research to practice. Designed for busy practitioners, Innovations translates research findings into clear, usable ideas. Each issue is devoted to one topic.

Recent issues have included:

Teaching Problem Solving to Students With MR A Family-Centered Approach to People With MR Teaching Students in Inclusive Settings Designing Positive Behavioral Support Plans by M. Agran \& M. Wehmeyer by L. Leal

by M. A. Demchak

by L. Bambara \& T. Knoster

\section{Call for Contributors}

Submissions of proposals for the 2001 series are invited. Potential contributors are requested to prepare a 2-3 page proposal including a description of the topic and its importance, an outline of the content and references. If a proposal is accepted, a full manuscript will be invited for review. The deadline for the next round of review is October 1, 2000. Mail 15 copies of the proposal to Diane Browder, Editor of Innovations, Department of Counseling, Special Education, and Child Development, University of North Carolina at Charlotte, 9201 University City Boulevard, Charlotte, NC 28223-0001. For further information:

Dbrowder@email.uncc.edu 